\title{
A juventude como condição estigmatizante: relações entre desigualdade, violência e experiência escolar
}

\author{
Carina Viviana Kaplan \\ Universidade Nacional La Plata \\ Universidade de Buenos Aires \\ Conselho Nacional de Pesquisas Científicas e Técnicas
}

\section{Resumo}

Considerando que os limites da estigmatização e a exclusão transformam-se em processos de atuoexclusão, por meio da força dos mecanismos inconscientes da dominação simbólica, torna-se imperioso identificar os pontos de vista dos jovens. Constata-se hoje um discurso dual sobre os e as adolescentes e jovens: são a promessa do futuro e, ao mesmo tempo, violentos criminosos que ameaçam a "tranquilidade social". Esse trabalho, portanto, pretende contribuir para facilitar uma virada analítica no campo da pesquisa sobre violência nas escolas que se distancie dos enfoques hegemônicos próprios da sensatez penal e do racismo biologicista. 0 termo "violência" na pesquisa socioeducativa tem uma diversidade de significados, inclusive contraditórios, e em vários dos quais mantém parte daqueles que provêm do sentido comum e de ditos paradigmas científicos hegemônicos. Trata-se, como desafio e utopia, de mudar esta visão, que tende a se impor como verdade.

Palavras-chave: Jovens. Estigmatização. Violência. 


\section{Youth as a stigmatizing condition: relations between inequality, violence and experience in school}

Considering that, at their limit, stigmatization and exclusion become processes of self exclusion, through the strength of unconscious mechanisms of symbolic domination, it becomes imperious to evidence the points of view of youth. Today, one perceives a dual discourse about adolescents and youth: they are the promise of the future and, at the same time, violent criminals who threaten "social tranquility". This paper, therefore, intends to contribute to enable an analytic change in the field of research about violence in schools, far removed from the hegemonic approaches characteristic to penal common sense and biologistic racism. The term "violence", in socio educational research, takes on diverse meanings, including contradictory ones - several of which partly incorporate meanings which stem from common sense and supposed hegemonic paradigms. Changing the vision that tends to impose itself as a truth is treated in this article as a challenge and a utopia.

Keywords: Youth, Stigmatization, Violence.

\section{La juventud como condición estigmatizante: relaciones entre desigualdad, violencia y experiencia escolar}

Al tener presente que los límites de la estigmatización y la exclusión se transforman en procesos de auto-exclusión, a través de la fuerza de los mecanismos inconscientes de la dominación simbólica, se torna imperioso vislumbrar los puntos de vista de los jóvenes. Se constata hoy un discurso dual sobre los y las adolescentes y jóvenes: son la promesa del futuro y al mismo tiempo violentos criminales que amenazan la "tranquilidad social". Este trabajo, por tanto, pretende contribuir para facilitar una virada analítica en el campo de la investigación sobre violencias en la escuela que se distancie de los enfoques hegemónicos propios de la sensatez penal y del racismo biologicista. El término "violencia" en la investigación socioeducativa tiene una diversidad de significados, incluso contradictorios, y en varios de los cuales mantienen parte de aquellos que provienen del sentido común y de dichos paradigmas científicos hegemónicos. Se trata como desafío y como utopía, cambiar esta mirada que tiende a imponerse como verdad.

Palabras clave: Jóvenes. Estigmatización. Violencia. 


\section{Introdução}

As relações entre a condição juvenil e a condição estudantil foram variando ao mesmo tempo em que se verificam transformações na constituição de subjetividade. Um percurso sócio-histórico e sociopolítico sobre a problemática do desemprego e a exclusão social em âmbito internacional - e na América Latina, em particular - deixa em evidência que os jovens foram um dos grupos sociais mais feridos nas últimas décadas e que o ensino médio ou fundamental, sob as condições estruturais do desemprego e a precariedade, foi debilitandose em sua promessa de igualdade. Considerando-se que o trabalho e a escola, como experiências culturais, constituem elementos estruturantes na produção da existência individual e coletiva, perguntamo-nos acerca das amarras subjetivas sobre as quais os jovens estudantes constroem sua identidade.

Especificamente, a integração das novas gerações à vida social plena, a partir de sua trajetória educativa, representa um dos mais importantes desafios para as políticas públicas educativas e para o sistema escolar, para os quais a pesquisa científica deve realizar uma importante contribuição. 0 certo é que os e as jovens, ao nosso entender, historicamente têm sido relegados pela condição da subalternidade que prevalece sobre eles. Se adotarmos uma perspectiva de longo alcance, observamos que foi fabricado um olhar social estigmatizante. As consequências das políticas aplicadas durante a década de 90 e a profunda crise dos primeiros anos do presente século acentuaram esse fenômeno, e os jovens tornaram-se novamente alvo privilegiado das formas da exclusão material e simbólica.

Sob o pressuposto de que a violência é construtora da subjetividade, perguntamonos sobre os processos e as experiências de subjetivação que produzem os jovens escolarizados em torno da violência e suas relações com a desigualdade social. É preciso advertir que grande parte dos discursos hegemônicos que constroem os meios de comunicação sobre o fenômeno da violência no âmbito educativo está permeada por um olhar próximo ao positivismo criminológico (lembrando os postulados de Lombroso acerca da delinquência como comportamento inato). A produção deste tipo de doxa determinista biologicista la que também poderíamos denominar como racismo biologicistal produz um mundo de ideias sensato, sob a aparência de um consenso social, que fabrica e dissemina crenças tais como que os pobres são, em essência, intelectualmente inferiores, ou violentos, ou preguiçosos, ou delinquentes, pela sua (suposta) natureza, ou herança familiar, ou dotação genética individual (Kaplan, 2010).

Partindo do pressuposto de que os jovens historicamente foram inferiorizados, e por meio do material recolhido em intensas entrevistas grupais realizadas com adolescentes e jovens estudantes do ensino médio de escolas argentinas 
da província de Buenos Aires ${ }^{1}$, surge uma das hipóteses substantivas de grande transcendência para repensar as relações entre desigualdade, violência e jovens: os sem sentidos das vidas submersas na exclusão são o pano de fundo da violência, entendida esta como construção simbólico-subjetiva e como relação social.

0 conceito de violência simbólica compõe a perspectiva na qual nos colocamos para analisar aquelas situações de violência que não são percebidas como tais,ou seja, conduz a uma avaliação sobre os mecanismos ocultos e inconscientes da reprodução de uma ordem social desigual, da injustiça social, e sobre a impossibilidade de muitos jovens terem uma vida digna. Essa conceptualização nos ajuda a vislumbrar aquela violência com que se convive cotidianamente, sem que seja identificada como tal por aqueles que a padecem. Esse questionamento consiste em um alerta aos responsáveis por estabelecer as políticas educativas, em especial àqueles responsáveis pela formação e capacitação dos professores, para erguer e transmitir uma perspectiva científica crítica alternativa à da patologização e criminalização dos estudantes.

Considerando que os limites da estigmatização e a exclusão transformam-se em processos de autoexclusão, por meio da força dos mecanismos inconscientes da dominação simbólica, torna-se imperioso enxergar os pontos de vista dos jovens, aqueles que entrevistamos nas escolas, para colocar sob tensão a eficácia da máquina da exclusão. Constata-se hoje um discurso dual sobre os e as adolescentes e jovens: são a promessa do futuro e, ao mesmo tempo, violentos criminosos que ameaçam a "tranquilidade social". A linguagem penal adquire protagonismo. 0 medo extensivo a que os jovens cometam homicídios não condiz com os fatos e as estatísticas, mas prevalece como eixo para justificar o olhar social da periculosidade. Esse medo social tem história. Os medos constituem experiências emocionais culturais e localizadas.

Este trabalho, portanto, pretende colaborar para facilitar uma virada analítica no campo da pesquisa sobre violências na escola que se distancie dos enfoques hegemônicos próprios do senso penal e do racismo biologicista. 0 termo "violência" na investigação socioeducativa tem uma diversidade de significados, inclusive contraditórios, e em vários destes mantém parte daqueles que provêm do sentido comum e de ditos paradigmas científicos hegemônicos. É um desafio e uma utopia mudar o olhar que tende a impor-se como verdade. Para isso, é necessário primeiro historiar o olhar social estigmatizante, inclusive racista, que se tem construído a respeito dos jovens em contextos de forte diferenciação e desigualdade, demonstrando que subjaz um discurso social que tenta impor-se como verdade: a imagem do juvenil subalterno como delinquencial tem raízes profundas em nossa matriz social. Argumentar que alguns jovens são delinquentes por herança ou

1. Os projetos de pesquisa em andamento estão inscritos no Programa de Pesquisa sobre Transformaciones Sociales, Subjetividad y Procesos Educativos - dirigidos por Carina Kaplan -, com sede no Instituto de Investigaciones en Ciencias de la Educación, Facultad de Filosofía y Letras, Universidad de Buenos Aires. 
por natureza é expressão desse tipo de crença. Podemos dizer que se trataria de uma forma de racismo que "[...] consiste em caracterizar um conjunto humano mediante atributos naturais, associados por sua vez a características intelectuais e morais aplicáveis a cada individuo relacionado com este conjunto e, a partir daí, adotar práticas de inferiorização e exclusão" (Wieviorka, 2009, p.13).

\section{Uma perspectiva sócio-histórica sobre o processo de criminalização das infâncias e das juventudes}

A história moderna do Ocidente vem relacionando a periculosidade social aos adolescentes e jovens. De uma perspectiva sócio-histórica e cultural, Robert Muchembled (2010), em sua história de violência, analisa o comportamento agressivo na Europa Ocidental desde o século XIII até a atualidade. A palavra "violência" aparece no começo do século XIII; deriva do latim vis, que significa força, vigor, e caracteriza um ser humano de caráter iracundo e brutal. 0 termo teria sido adotado para descrever as expressões mais trágicas de tal vigor, associado aos homens, e foram múltiplos saberes e teorias que se encarregaram de caracterizálo. 0 Ocidente inventa a adolescência por meio de uma tutela simbólica sobre uma faixa etária considerada como turbulenta e insubmissa aos olhos do poder estabelecido. 0 temor a não poder controlar as energias da juventude opera como pano de fundo.

A ideia que postulamos em nosso processo de pesquisa sobre os jovens em turbulência (Kaplan, 2011'a) representa um convite a refletir, com um enfoque sócio-histórico e pedagógico, sobre as duas caras da moeda: aqueles podem ser pensados como indisciplinados, descontrolados ou rebeldes, desafiantes do status quo. Transgredir não é sinônimo de delinquir,mesmo que se queira mostrar determinado discurso penalizante que dissocia as causas (sociais) das consequências (individuais e grupais), evitando todo tipo de compreensão das circunstâncias e os processos que originaram e se transformaram em dito ato de rebeldia ou oposição. Este discurso social dual sobre os jovens não é novo e precisa ser considerado a longo prazo. 0 próprio Muchembled, em suas reflexões sobre a delinquência juvenil, evoca:

Nos séculos XVI e XVII, a juventude, termo que na época designava a adolescência, possui uma consideração ambígua. É um tempo portador de promessas e uma idade "obscura e devassa", a pior e a mais perigosa de todas, segundo certos autores. Os moralistas ingleses não se cansam de estigmatizar os pecados dos jovens, especialmente seus costumes liberais. (Muchembled, 2010, p. 348).

A imagem positiva, detém-na o jovem aprendiz virtuoso, enquanto o adolescente 
mau transcorre sua vida concretizando comportamentos incivis. Portanto, o medo generalizado em relação aos jovens fica circunscrito à condição social de certos grupos de jovens de quem se supõe a propensão ao delito. A moral cristã dominante tenta incitar aos homens jovens a colocar sua força e vitalidade a serviço da ordem estabelecida, sob a promessa de aceder a uma existência adulta completa, agradável e prestigiosa.

Em termos de Goffman (1989), digamos que ser adolescente se transforma, assim, numa condição estigmatizante, isto é, portador de um atributo concebido como intrínseco que tem a qualidade de vergonhoso e ameaçador. As propriedades simbólicas atribuídas à sua identidade social, e que os torna diferenciados, vinculam-se ao desenfreamento. 0 efeito dessa crença deve sua eficácia simbólica ao adjudicar a rebeldia, como fato negativo, aos jovens, transmutando-a num fato exclusivo deste grupo social.

As mutações sociais, econômicas e culturais da Europa do século XVIII transformam essa visão dualista. No passar do século XVIII ao XIX, a delinquência juvenil adquire importância como problema social. Neste ponto, há um debate entre os historiadores a respeito do surgimento de dito fenômeno, já que parece indicar que emerge de maneira brusca no justo momento em que aparece o conceito de adolescência, quando até então se falava mais vagamente de "jovens casadeiros". Essa discussão merece localizar-se num marco mais amplo.

0 processo de controle da violência sanguinária e dos costumes dissolutos dessa faixa etária registrou importantes triunfos no século XVII e sobretudo no século XVIII. Afetou principalmente os meios mais acomodados e continuou logo com mais dificuldades, influindo nas camadas populares. (Muchembled, 2010, p. 349).

A arquitetura sobre a delinquência juvenil reproduz essas diferenças sociais. Instaura-se como um separador social que permite distinguir o joio do trigo: por um lado, existe a juventude dourada, que transita docilmente pela puberdade, e por outro estão os jovens de setores subalternos que continuam brigando com canivetes e serão qualificados como selvagens, vulgares e ordinários. Segundo Bourdieu (2000), podemos falar de duas instâncias: um primeiro momento objetivo, em que a distância se transforma em diferença; e um segundo momento simbólico, no qual essa diferença se converte em distinção.

0 emprego de uma linguagem penal transforma profundamente o olhar coletivo sobre a infância e o período de transição até a vida adulta. A imagem de brutalidade excessiva que havia predominado para todos se tornará mais seletiva e se imputará a uma minoria julgada como "anormal", que se abandona aos golpes e às lesões; em particular, que lhe atribuem homicídios. Efetivamente, as distinções e taxonomias sociais operam comparando indivíduos e grupos, por distância ou proximidade, estabelecendo parâmetros de normalização principalmente implícitos (Kaplan, 2008). No começo do século XIX, na França, o jovem tipificado como delinquente 
é individualizado por seu contraste com o jovem normal. “Mais adiante, a prática judicial se carrega de conotações pejorativas que se contrapõem claramente ao pivete malandro de extração obreira, com o menino inocente e puro, pertencente às classes médias ou superiores" (Muchembled, 2010, p. 350). Isso também ocorre com as adjetivações depreciativas sobre os adolescentes homens quando se pretende explicar sua suposta afeição à delinquência.

Mencionemos, assim mesmo, que a figura da mocinha delinquente praticamente não aparece. Por exemplo, na Inglaterra, nesse começo de século XIX, a percepção do problema do aumento das malfeitorias por parte dos adolescentes não incrimina as mulheres. 0 sistema judiciário persegue os homens permeados pela sua condição marginal. 0 estereótipo feminino, por sua vez, está construído em volta da imoralidade sexual. 0 indubitável é que a concentração dos medos sociais nos adolescentes de setores populares expande-se pela Europa toda, especialmente na Inglaterra e na França, na segunda metade do século XIX.

É nesse período, então, que se impõe o conceito de delinquência juvenil para caracterizar a agressividade de uma minoria de adolescentes e jovens nas grandes cidades industriais.

As continuidades que cabe observar desde há séculos em matéria de violência e homicídio se referem à proclamação da hegemonia masculina. Na Suécia, por exemplo, os combates e assassinatos conservam características idênticas desde o século XVI até o século XX. Frequentemente são consequência de um ataque de raiva, após uma briga ou uma provocação relativa à questão de honra ou de dívidas, agravada pelo álcool. Os protagonistas pertencem sobretudo às camadas inferiores da população. Porém, seu número diminui muito durante esse período. As classes médias são as primeiras em pacificar-se, provavelmente, porque seus membros encontram outros métodos para afirmar sua virilidade. (Muchembled, 2010, p. 353).

A rua deixa de ser o cenário principal dos enfrentamentos e se transforma em grande parte ao espaço privado. A violência física tem-se tornado residual nas sociedades ocidentais do século $X X$, de acordo com a minuciosa análise de Muchembled, em consonância com a perspectiva de Norbert Elias (1993), na sua análise do processo civilizatório. Cas Waters (2008) afirma que

[...] até finais do século XIX, em um longo período de formalização das boas maneiras e o disciplinamento das pessoas, as emoções "perigosas" tais como aquelas relacionadas com a violência física (incluindo a violência sexual) passaram a ser evitadas, reprimidas e negadas de maneira automaticamente crescente, ou seja, gradativamente reguladas pelos próprios medos mais íntimos de uma consciência muito mais rígida e autoritária. 0 tipo de personalidade dominada pela consciência se estava constituindo para se tornar dominante. No século XX, houve uma informalização das boas maneiras e uma "emancipação das emoções: as emoções que tiveram sido negadas e reprimidas (re)adquirem acesso à consciência conseguindo maior aceitação nos códigos sociais". (Waters, 2008, p. 81). 
É conveniente lembrar a ideia exposta por Norbert Elias (1993) demonstrando que civilização e violência não são antíteses. 0 homem está em processo contínuo para civilizar-se, ou seja, para melhorar seus padrões de conduta e de comportamento, prevenindo os conflitos baseados na violência física, tratando de priorizar o diálogo e a construção do argumento como instrumento principal da defesa de seus interesses. É sob o monopólio da força física por parte do Estado e a estabilidade crescente dos órgãos centrais da sociedade que o autodomínio das emoções e do afeto se converte em uma segunda natureza do comportamento dos indivíduos. Elias (2000) sustenta que essa aprendizagem dos autocontroles nunca é sem dor ou suave e sempre deixa feridas.

Pois bem, após nosso breve, porém necessário percurso sócio-histórico, estamos em condições de sustentar que em todas as épocas se verifica a dificuldade da inserção dos adolescentes e jovens no mundo adulto. Os bandos que, aos olhos das gerações adultas, costumam ser percebidos como gangues de adolescentes selvagens - e que tingem grande parte das representações simbólicas nas relações entre as gerações - podem, porém, oferecer aos jovens uma socialização entre iguais e funcionar como válvula de escape perante os olhares estigmatizantes, as injustiças sociais e os sem sentidos das suas existências individuais e sociais.

Nos processos de designação e autodesignação de rótulos e tipificações - no nosso caso, a de "violento" -, põe-se em jogo uma dinâmica de poder entre a atribuição a um suposto ser de umas determinadas qualidades vinculadas às aparências. A aparência de pobre lo hábito corpóreo como indício de classe ou, o que é equivalente, o corpo tratado socialmente), por exemplo, está associada à de ser violento e à incivilidade em geral, gerando uma sorte de discurso racista sobre os jovens marcados pela condição de marginalidade e subalternidade. Um comportamento social de certa qualidade - violento - passa, dessa maneira, a ser tratado como um dado essencial de um tipo de individuo ou de determinado grupo. Este controle de aparência pode ser mais brutal quando se exerce o poder estatal sobre os indivíduos e grupos subordinados.

Assim como Norbert Elias (2000) expressa que é a miséria da sociedade que torna miseráveis as pessoas que nela habitam, nós nos afirmamos na ideia de que são as sociedades que tornam violentas as pessoas, e não a natureza individual vista como propriedade essencial. Precisamente, isto constitui um suposto de partida da perspectiva socioeducativa crítica que vimos construindo: as biografias pessoais e as trajetórias grupais estão entrelaçadas e carregam os signos de época em sociedades particulares. É no tecido social e na memória histórica dos homens que se constrói o caráter pessoal. Digamos que os sujeitos sociais, indivíduos e grupos, tornam-se "perigosos". Embora seja verdade que a força dos discursos individualizantes e autoresponsabilizadores sobre a produção da desigualdade consiste em que,por meio de modos sutis, mas não por isso menos eficientes, estes discursos impactam sobre as formas de pensar, atuar e sentir dos sujeitos, isto é, sobre as formas da autoconsciência. 


\section{Os sentidos da violência: testemunhos de jovens de escolas de ensino médio da Argentina}

Dado que a violência é uma qualidade relacional, entendemos que, para interpretar as relações entre violência e jovens, desde o enfoque alternativo ao hegemônico, é necessário considerar - conforme mostra Norbert Elias em suas análises - que, em toda época, os jovens precisam primordialmente de quatro esteios: al perspectivas de futuro, em sociedades onde ainda vivam sem projetos; b) a possibilidade de referenciar-se em um grupo de pertença; c) um ideal que dê sentido à sua vida e, ainda mais, que seja superior à própria vida; d) o gozo do respeito e da estima social (Kaplan 2011b). A violência se vincula às experiências daqueles que não conseguiram se sentir reconhecidos ou que experimentam sentimentos de descrédito amplo, de rejeição, de exclusão.

Sob estas considerações, apresentam-se os resultados de um estudo de matriz qualitativa que realizamos com jovens de 13 a 19 anos, que frequentavam, no ano $2009^{2}$, duas escolas de ensino médio da cidade de La Plata, na província de Buenos Aires, que recebem dois setores sociais diferentes. Por meio da modalidade de grupos focais (Valles, 1997), entrevistou-se um total de 49 alunos, divididos em sete grupos, segundo a idade, o ano do curso (segundo e último ano do ensino médiol e o gênero.

Indagaram-se questões relacionadas com a constituição da alteridade, a produção de vínculos entre iguais, as determinações dos comportamentos sociais violentos, a construção da categoria de "aluno violento", o lugar da autoridade. Durante diversos momentos das entrevistas, utilizaram-se recursos projetivos que incluíram fotografias de jovens em diferentes cenários, assim como situações e frases emblemáticas usuais na linguagem dos jovens.

Os alunos que formaram parte dos grupos focais cursavam o ensino médio em duas escolas públicas com características bem definidas:

- Escola 1: trata-se de uma escola localizada em uma região central da cidade, sem um reconhecimento especial pela sua qualidade acadêmica,mas sim pela sua condição de formar um quadro de estudantes pertencentes a lares de nível socioeconômico (NSE) médio e médio baixo, grande parte deles moradores da periferia.

- Escola 2: trata-se de uma escola de ensino médio considerado "tradicional" dentro da cidade de La Plata, de nível acadêmico especialmente destacado entre os moradores, localizada na região central, e na qual predominam estudantes pertencentes a lares de nível socioeconômico (NSE) médio a médio alto. As vagas nesta escola são limitadas e pouco acessíveis, devido à grande demanda por

2. 0 trabalho de campo tem sido realizado no marco do projeto de investigação UBACyT F014/08, "Desigualdad, violencias y escuela: dimensiones de lasocialización y lasubjetivación", que tem como Diretora Carina Kaplan (Secretaria de Ciência e Técnica da Universidade de Buenos Aires), com sede no Instituto de Investigações em Ciências da Educação, Faculdade de Filosofia e Letras, Universidade de Buenos Aires. 
matrícula. A amostra configurou-se conforme especificado no Quadro 1.

Quadro 1: Amostra da pesquisa

\begin{tabular}{|c|c|c|c|c|}
\hline Grupo & Escola & NSE Predominante & Idades/Ciclo & Gênero \\
\hline 1 & Escola 1 & Médio-Baixo & ESB -13 a 15 anos & Feminino \\
\hline 2 & Escola 1 & Médio-Baixo & Polimodal -17 a 19 anos & Masculino \\
\hline 3 & Escola 1 & Médio-Baixo & ESB -13 a 15 anos & Masculino \\
\hline 4 & Escola 1 & Médio-Baixo & Polimodal -17 a 19 anos & Feminino \\
\hline 5 & Escola 2 & Médio-Alto & Polimodal -17 a 18 anos & Misto \\
\hline 6 & Escola 2 & Médio-Alto & ESB -13 a 14 anos & Masculino \\
\hline 7 & Escola 2 & Médio-Alto & ESB -13 a 14 anos & Feminino \\
\hline
\end{tabular}

Obs.: Educação Secundária Básica:primeiro ciclo; Polimodal:ciclo superior.

Dos resultados lançados pelo vasto e rico material surgido das entrevistas com os jovens escolarizados, infere-se uma série de dimensões analíticas.

Para fins da argumentação que mantenho neste trabalho, vou referir-me às relações de significação que os estudantes estabelecem entre violência e papel da escola; as distinções segundo tribos urbanas; a construção do outro como ameaça; o uso da linguagem carcerária; e a diferenciação social a respeito da violência na escola.

\section{As relações entre violência e escola}

A escola aparece recorrentemente, segundo os jovens entrevistados, como o segundo espaço de pacificação (o primeiro é o núcleo familiar). No entanto, não deixam de evidenciarem-se contradições. A função da "formação" ou da "instrução" aparece num lugar subsidiário em face da função de "tirar das ruas" ou das "amizades ruins".

Podem ensinar na escola a não ser violento, ou que com a violência não se resolvem os problemas, que se resolvem dialogando. (Aluna mulher, grupo de 17 e 19 anos, Escola 1, NSE médio-baixol.

Para mim, ao contrário, o único motivo que te ajuda a ser menos violento é porque te deixa fora das ruas, que aí sim é onde você aprende a ser violento. Ficar menos tempo nas ruas. 0 assunto passa por aí. (Aluna mulher, grupo de 13 e 15 anos, Escola 1, NSE médio-baixol. 
A escola te distancia de amizades ruins. E por isso você acaba sendo menos violento. E talvez,quando você se encontra novamente com os amigos, volta a ser de novo violento. Ou talvez não, por ter aprendido. (Aluno homem, grupo de 13 a 15 anos, Escola 1, NSE médio-baixol.

(...) Bom, na verdade é que um pouco te distancias, por ter a oportunidade de uma carreira ou de um futuro, terás menos oportunidades de ser um ladrão ou delinquente em geral. (Aluna mulher, grupo de 13 a 15 anos, Escola 2, NSE médio-alto).

A “junta”, como termo carcerário, aparece recorrentemente como condição ou explicação ao desenvolvimento de condutas violentas. Em todos os grupos, de todos os níveis socioeconômicos, surgiu o conceito de forma reiterada. Também a família tem um papel fundamental numa espécie de parceria com a escola. É aquela que decide o projeto escolar para seu filho:

Talvez outro rapaz, que os pais não se preocupam, termina sem frequentar a escola. $E$ com o passar do tempo, com os rapazes do bairro termina mal. (Aluno homem, grupo de 17 e 18 anos, Escola 2, NSE médio-alto).

Em qualquer caso, a escola aparece no discurso dos jovens como uma situação de relativo privilégio.

Nós temos a sorte de poder vir à escola. Ou nos mandam ou vimos, mas podemos. Outros não podem. (Aluno homem, grupo de 17 e 19 anos, Escola 1, NSE médio-baixo).

Há muitos que não querem vir, mas outros não podem. Ou não têm ninguém que diga: "você tem que ir para a escola, senão você não vai progredir..." (Aluna mulher, grupo de 13 a 14 anos, Escola 2, NSE médio-alto).

Entre os alunos de ensino superior da escola de nível socioeconômico médioalto conseguimos escutar o seguinte diálogo, em que aparece a escola como espaço de possibilidade:

E: Se vocês tivessem que pensar como solucionar a violência na sociedade, como fariam?

A1: Talvez, dando-lhes trabalho, porque não ter trabalho leva a pessoa a roubar, porque tem que se alimentar de algo e precisa uma moradia.

A2: Também a educação influencia muito.

E: Falamos da escola?

A2: Sim. É importante

E: Mas, por quê? Porque ensina matemática, língua e outras coisas?

A1: Não, é pelos valores

E: A escola transmite valores? 
A2: E...talvez sim

A1: Talvez não ensinam, mas a gente vai adquirindo com os colegas, com a sociedade que se forma...

A3: Não, a escola não se ocupa muito de transmitir valores, mas se aprendem.

A: Não é a mesma coisa um rapaz que vai à escola e outro que não vai.

A3:São duas coisas diferentes um rapaz que vai e outro que não vai, porque o que vai sabe relacionar-se...

$E$ : Mas, como é que a escola te ensina a relacionar-te?

A3: Não, não é que a escola te ensina, senão que você aprende sozinho. Mas porque estás aí.

(Alunos homens, grupo de 13 e 14 anos, Escola 2, NSE médio-alto).

Por sua vez, nos diálogos, os alunos dos primeiros anos também põem de manifesto a reclamação de maior contenção ou sustento socioafetivo por parte da escola:

A3: Eu vejo a escola como vir ao colégio e mais nada. Talvez há outros rapazes que precisam e o colégio não se involucra no que deve involucrar-se para ajudar a esses rapazes. Os professores dizem que, na realidade, o colégio tem que ser de inclusão, a segunda casa e tudo que dizem, mas não se concretiza...

A1: Talvez não seja algo que passe aqui, aqui é bastante inclusivo.

(Grupo misto de 17 e 18 anos, Escola 2, NSE médio-alto).

Também, frente à dificuldade da família de brindar determinados recursos, a escola aparece como um lugar de possibilidades. Para estes grupos de jovens, as razões da violência estariam mais relacionadas com estes itens:a falta de oportunidades e a desigualdade; as violências exercidas sobre ele; as necessidades e carências; e os lares "malconstruídos". Podemos afirmar, aprofundando-nos nas entrevistas, que os jovens identificados como violentos teriam sido previamente violentados, situação que se encontra invisível para o resto da sociedade.

A sociedade em geral suspeita mais dos pobres por uma questão de preconceito, digamos, muita gente política - digamos, rica - roubou e tenho certeza que deixou muitas mais mortes que a que deixa a delinquência hoje em dia, (Estudante homem, grupo de 17 e 19 anos, Escola 1, NSE médio-baixo).

\section{As diferenças segundo tribos urbanas}

Para a maioria dos jovens entrevistados, dois dos principais indicadores de um potencial "jovem violento" são as roupas e o corte de cabelo. Para definir o aspecto violento, os jovens utilizaram os seguintes indicadores entrelaçados do hábito corpóreo: gorros; tênis "de marca"; conjuntos esportivos em contextos 
não esportivos; "roupa que você compra na La Salada ${ }^{3}$ "; determinados cortes de cabelo; cabeças raspadas.

Para definir o aspecto "não violento", ao contrário, utilizaram-se as seguintes características: ternos; gravatas; camisas lisas; vestidos de festa; penteados cuidados e caprichados ("como para uma festa"); suéter; vestimenta casual, como camisas xadrez ou estampadas e jeans.

Cortes de cabelo, vestimentas, poses e tonalidade da pele poderiam funcionar como credenciais quase perfeitas de identificação do jovem violento.Inclusive, algum deles já considerou que há uma típica "cara de pobre". Em definitivo, poderíamos dizer que, com algumas exceções, as vestimentas aparecem como melhor indicador do que o rosto ou a cor da pele, como se a nova pele fosse têxtil - muito embora a análise aprofundada dos depoimentos permita constatar que, na verdade, esses atributos se percebem imbricados e hierarquicamente dispostos.

Somente o rosto não é algo que se possa distinguir se é violento ou não violento. Necessitas conhecê-lo ou pelo menos ver mais dele: como se veste, com quem anda... (Aluno homem, grupo de 13 e 14 anos, Escola 2, NSE médio-alto).

\section{A construção do "outro" como intimidante}

O comentário "se vejo alguém com essa cara, atravesso a calçada", escutado em vários momentos das entrevistas, é uma manifestação verbal ou efeito simbólico da exclusão. A discriminação implica a desvalorização do outro, a quem se desconhece, a quem se teme, de quem se supõea necessidade de isolar-se e proteger-se. É outro ao qual se dá um nome, a quem se classifica e define le confinal, por uma associação que é prévia. Por exemplo, aquele que é pobre e possui determinados traços físicos é associado com o que é ladrão e/ou violento. Chamou-nos atenção a constatação de que, ao longo dos intercâmbios mantidos com os estudantes, quem julga e discrimina outro que é portador de hábitos corpóreos associados ao atributo "violento" pode reconhecer-se com os mesmos traços, e, não obstante, seguir sustentando que o outro é ameaçante. De alguma forma, funciona um processo de auto atribuição dessa adjetivação negativa. A outra face do preconceito se revela quando os adolescentes entrevistados descrevem um jovem sorridente, de tez clara, loiro, numa postura que demonstra certa segurança de si mesmo, como não potencialmente violento.

Em outros termos, no imaginário dos alunos existe uma construção prévia

3. La Salada é uma feira onde se vende, entre outras coisas, roupa a um valor inferior a outras lojas. Um dos questionamentos que se fazem da feira é que vendem roupas "de marca", mas falsificadas (piratas), a um preço consideravelmente inferior ao do modelo original. 
do "outro", que também se traduz em diversas classificações sociais lque os estudantes reproduzem), como, por exemplo, diferenciar o tipo de escola em função da população que a ela concorre. Nesse sentido, não há distinção a respeito de, por exemplo, a oferta educativa, senão do status socioeconômico dos estudantes que a frequentam: escolas que, mesmo sendo do centro, são percebidas como de "menor nível", as escolas "dos bairros" (periféricas, desprotegidas, desiguais, de "pior nível"). Também dentro da categoria de "outro"se encontramos que concorrem às escolas privadas, sobre as quais não há uma ideia uniforme.

\section{A linguagem carcerária}

Reiteradamente lainda que com maior presença nos grupos pertencentes aos níveis socioeconômicos mais baixos) se observa um manejo de certa linguagem tumbero, que é como se denomina a linguagem carcerária. A utilização desta linguagem, em alguns casos, é parte do vocabulário habitual, ao mesmo tempo em que "fica bem" ante os outros. Os termos mais escutados durante as entrevistas com os grupos analisados foram os seguintes: colocar-se o cartaz (demonstrar aos outros que somos maus, violentos, perigosos); a junta (com quem se juntam; vinculação ao grupo a que pertence); corte (significa como; é o equivalente à muleta "tipo que", que empregam alguns jovens de classes sociais mais altas, os "chiques"); parar-se de mãos (responder com violência a uma agressão, um olhar, etc.); resgatar-se (acalmar-se, tranquilizar-se, não se drogar); gato (forma de chamar o outro ou à polícia); bonê (forma de chamar a polícia).

E: Você sabe de onde vêm essas frases?

A: Do presídio, não sei...

E: Sim, do presídio. Começa-se escutando frases que vêm do mundo "tumbero" dentro dos relacionamentos de vocês...

A: Bom, mas no nosso bairro é assim.

E: Por quê? Porque estiveram na prisão?

A: E... alguns sim, e outros porque de tanto escutar, acaba saindo.

(Aluna mulher, grupo de 13 a 15 anos, Escola 1, NSE médio-baixo).

Novamente, é importante destacar o fato de que essa linguagem é escutada nos grupos de níveis socioeconômicos tanto baixos quanto altos; e tanto entre aqueles que dizem conhecer ou ter por perto gente que esteve ou está vinculada à prisão, quanto entre aqueles que estão bem distantes dessas realidades em seu cotidiano.

É muito interessante ver as respostas que deram os jovens durante as entrevistas, quando tentam desnaturalizar a linguagem que empregam, não só porque as expressões constituem parte do seu cotidiano, são seus códigos, 
mas também porque as reconhecem como habituais em certos programas de televisão. 0 que resulta sugestivo é que, em geral, nesses programas em que se estigmatizam os jovens, associando-os invariavelmente a algum tipo de violência, descontextualizando suas situações de marginalidade e exclusão social, eles encontram ali algo que gera algum tipo de identificação. Reconhecem que há nesses programas "algo para aprender". Geralmente, como produto da "espetacularização" da violência que fazem os meios massivos de comunicação, gera-se uma imagem amedrontadora do jovem, que aparecem como perigosos e ameaçadores.

Se uma das formas para serem respeitados, segundo os jovens entrevistados, passa por inspirar medo no outro, então estes programas teriam "algo para ensinar". Constitui-se desta forma um circulo vicioso, a profecia autocumprida. Tanta ênfase se dá ao par jovens-violentos que finalmente eles, os aludidos, demonstram que podem lográ-lo. Desta forma, cumprem com o que a sociedade, aparentemente, espera deles. Se isto não implica adotar as posturas deterministas dos meios de comunicação, em todo caso deixa em evidência a falta de discursos alternativos, que mostrem que efetivamente existem outros mecanismos para fazer-se respeitar, sem necessidade de amedrontar o outro. Faltam discursos que mostrem que os jovens - sobretudo os pobres, que são os mais expostos a estes meios - não são uma massa homogênea e violenta e podem ser de outro modo, se lhes forem proporcionados os recursos (materiais, simbólicos, afetivos) de que necessitam. Evidentemente, como os jovens mencionam, a linguagem carcerária, os modos de comportar-se e sobreviver "estão em todos os lados", "todo o tempo", nas boates ${ }^{4}$, na escola, na TV. A diferença substancial que devemos marcar é que, nesses meios, nem todos se encontram representados do mesmo modo: os jovens "que têm dinheiro" (expressão empregada pelos jovens entrevistados) constituiriam a versão (e exceção) de sucesso.

\section{Diferenciação social, violência na escola}

Podemos sustentar que os estudantes entrevistados, que são produto das sociedades excludentes de mercado, são de certo modo conscientes de seus efeitos negativos.

Muitas vezes se rouba ou se ataca a alguém porque o outro tem e você não. Aqui há alguns que têm muito e outros que não têm nada de nada. 0 que não tem, tem raiva ${ }^{5}$. (Aluno homem, grupo de 13 a 15 anos, Escola 1, NSE médio-baixo).

\footnotetext{
4. Lugares para dançar.

5. Inveja.
} 
Em outras épocas talvez nem passasse. Os rapazes andavam na rua e brincavam com a bola da gente. Mas não havia muito para brigar. (Aluno homem, grupo de 17 a 19 anos, Escola 1, NSE médio-baixol.

A publicidade que você vê o tempo todo é outro assunto: mostram o melhor celular, a melhor roupa, férias... E um rapaz talvez não pode comprar nada disso. E então fica louco. (Aluno homem, grupo de 17 a 19 anos, Escola 1, NSE médio-baixo).

A1: Há muitas que por ser lindas, se pegam na saída e a desfiguram porque é linda.

A2: Por inveja.

E: Mas não podem tirar a beleza.

A2: Não, mas elas se conformam em bater e desfigurar-te.

E: Eu já escutei isso, mas não pensei que fosse assim.

A2: Sim, agora o fazem.

$\mathrm{E}: 0$ homem que é violento, vocês o veem como mais macho?

A3: Eles acreditam nisso, que vão ser mais espertos.

E: A mulher que exerce a violência física é menos feminina ou mais?

A2: Sim, menos.

E: Por que acreditam que o fazem então?

A3: Pelo mesmo, pra dizer "aqui estou, não vão passar por cima de mim. Não me olhes assim..."

(Aluna mulher, grupo de 13 a 15 anos, Escola 1, NSE médio-baixo).

0 que pareceria estar por trás de alguns conflitos entre estudantes - por exemplo, as surras entre colegas - é o desejo daquilo que "o outro tem e eu não", que nas mulheres se manifesta em expressões associadas à beleza, à vestimenta. 0 ter ou não ter não faz mais do que pôr de manifesto a estrutura desigual das posições e de poder destes jovens estudantes.

\section{Uma reflexão final}

Na Argentina, assistimos a um contexto de democratização, extensão e massificação da escola, a partir da Lei de Educação Nacional, vigente desde o ano 2006 (Lei $n^{\circ}$ 26.206/06). A Lei instaura, pela primeira vez na história nacional, a obrigatoriedade do ensino médio. A meta é incluir todas e todos os adolescentes e jovens no sistema escolar, o que implica uma transformação cultural profunda em relação ao tempo em que o ensino médio era pensado para uma elite: para os futuros governantes e para aqueles que dariam continuidade aos estudos superiores.

0 acesso ao ensino médio de setores sociais tradicionalmente marginalizados põe em xeque a reprodução da condição de privilégio dos setores sociais dominantes e acarreta uma série de desafios. É nessa trama que se produz o retorno a velhas 
justificações teóricas e discursos de ordem da doxa penalizante e estigmatizante, que, como no caso do determinismo biológico e do darwinismo social, possam explicar o fracasso daqueles que não foram "escolhidos" para o êxito escolar e social (em termos de ausência de atitudes cognitivas) por sua condição "natural" de pobreza ou porque são portadores de atributos intrínsecos como o "ser violento".

Por tudo isso é que em nossa trajetória de pesquisa nos interessa compreender, em uma perspectiva sócio-histórica, como foi construído um olhar negativo sobre os jovens e, por outro lado, como operam determinados mecanismos de exclusão e autoexclusão dos jovens no interior do sistema escolar, em que a qualidade de "violento" constitui um analisador significativo. Estamos em condições de sustentar que a atribuição do "ser violento" constitui uma operação eufemizada da sócio dinâmica da estigmatização que perpassa a condição juvenil e estudantil. Nos testemunhos recolhidos na pesquisa, os estudantes entrevistados dão conta desta imagem negativa que lhes é imposta, ao mesmo tempo em que, por momentos, se autoresponsabilizam. Podemos afirmar, como hipótese, que um dos efeitos simbólicos de dita imagem é uma interiorização, às vezes inconsciente,sob o ponto de vista sociológico.

$\mathrm{Na}$ construção de um olhar alternativo, é fundamental pensar o lugar simbólico da escola. É sobretudo em cenário de alta seletividade e exclusão, de discriminação e violência, que a escola alcança um valor único e inevitável. Ainda que com todas as suas problemáticas, a instituição escolar continua sendo um espaço poderoso para a resistência cultural e a revolução simbólica. Apresenta-se como um dos poucos espaços sociais com força suficiente para dar nomes às crianças e aos jovens desprotegidos e trazer de volta as vozes caladas(pela originária condição socioeconômical,as identidades culturais singulares, a origem étnica ou as qualidades diferenciais para o aprendizado. Na escola visualizamos ainda vestígios da promessa de inclusão social - se a escola, por si mesma, não pode transformar as determinações estruturais e materiais de vida que condicionam as trajetórias dos estudantes, está em condições de potencializar subjetivamente estes estudantes no que se refere ao seu próprio valor social e escolar. Os limites objetivos e as esperanças subjetivas entram em tensão nas escolas democráticas. Ali a mudança do olhar sobre os alunos se torna tão necessária quanto possível.

\section{Referências}

BOURDIEU, Pierre. (1987). Cosas dichas. Barcelona, Gedisa, 2000.

ELIAS, Norbert. El proceso de la civilización. Investigaciones sociogenéticas y psicogenéticas. Madrid, Fondo de Cultura Económica, 1993.

ELIAS, Norbert. La sociedad de los individuos. Barcelona, Península, 2000.

GOFFMAN, Ervin. Estigma. La identidad deteriorada. Buenos Aires, Amorrortu, 
1989.

KAPLAN, Carina Viviana. Talentos, dones e inteligencias. El fracaso escolar no es un destino. Buenos Aires, Colihue, 2008.

. La confianza hacia las posibilidades de aprender de los alumnos: un umbral necesario para abordar la diversidad sociocultural en la escuela. In: Vergara Fregoso, Martha y Alegría Ríos Gil, Josefa (Coords.): La diversidad cultural: retos y perspectivas para su atención educativa - Argentina, Colombia, Guatemala, México y Perú. Jalisco, México: Editorial Universidad de Guadalajara, 2010, p. 93-112.

. Jóvenes en turbulencia. Miradas críticas contra la criminalización de los estudiantes. In: Revista Propuesta Educativa. Buenos Aires, FLACSO, No 35, 2011a Disponível em: <http://www.propuestaeducativa.flacso.org.ar/articulo. php?id=26\&num=35>. Acessoem: 12 nov. 2011 a.

. La sensibilidad por la violencia como experiencia cultural y educativa en sociedades de desigualdad. El caso de losjóvenes. Caderno de Estudos Sociais. Recife, Fundação Joaquim Nabuco, vol. 25, n. 1, p. 45-52, jan./jun. 2011 b.

MUCHEMBLED, Robert. Una historia de la violencia. Del final de la Edad Media a la actualidad. Buenos Aires, Paidós, 2010.

WATERS, Cas. La civilización de las emociones: Formalización e informalización. In: Kaplan, Carina Viviana (coord.). La civilización en cuestión. Escritos inspirados en la obra de Norbert Elias. Buenos Aires, Miño y Dávila, 2008.

VALLES, Miguel. Técnicas cualitativas de investigación social. Madrid, Síntesis Sociología, 1997.

WIEVIORKA, Michel. Racismo. Una introducción. Barcelona, Gedisa, 2009.

Recebido em agosto de 2012

Aprovado em outubro de 2012

Carina Kaplan é doutora em Educação pela Universidade de Buenos Aires e mestre em Ciências Sociais e Educação pela FLACSO, Argentina. Professora titular da Cátedra Sociologia da Educação da Faculdade de Ciências Humanas e Ciências da Educação da Universidade Nacional de La Plata; Professora Adjunta da Cátedra Sociologia da Educação da Faculdade de Filosofia e Letras da Universidade de Buenos Aires. Diretora do Programa de Pesquisa sobre Transformações Sociais, Subjetividade e Processos Educativos com sede no Instituto de Pesquisas em Ciências da Educação da Universidade de Buenos Aires. Pesquisadora de Carreira do Conselho Nacional de Pesquisas Científicas e Técnicas - CONICET. Email: kaplancarinåagmail.com 